La tarde del pasado 25 de junio en la Sala 24-05 se realizó la primera sesión del Consejo de Facultad de Humanidades y Ciencias Jurídicas, iniciando con ello un nuevo período de gobierno de la Facultad encabezada por el Doctor Luis Alfredo Lobato. Además de los miembros del Consejo de Facultad ampliado, participaron invitados especiales quienes escucharon el informe del Decano relacionadas con las líneas del Plan de Trabajo del período 2014-2018

En un ambiente cordial y de unidad, los asistentes plantearon propuestas e inquietudes con el fin de fortalecer el Plan de Trabajo. Un Plan que en palabras del Decano pretende recoger las necesidades y aspiraciones de todos los sectores universitarios representados en el Consejo y de la sociedad en general.

A continuación reproducimos de manera íntegra la declaración del Consejo de Facultad de Humanidades y Ciencias Jurídicas.

\title{
DECLARATORIA DEL INICIO DE SESIONES DEL CONSEJO DE FACULTAD EN EL PERÍODO 2014-2018
}

140<smiles>[Li]</smiles>

Consejo de Facultad de Humanidades y Ciencias Jurídicas en su sesión de inicio de gestión académica 2014-2018, se dirige a los miembros plenos, directores $y$ coordinadores de unidades académicas e invitados especiales, para declarar su apego a la Misión, Principios y Objetivos que orientan el quehacer de nuestra Alma Mater, la Universidad Nacional Autónoma de Nicaragua, Managua (UNANManagua).

Así también reafirmamos el compromiso de ejecutar el Plan Estratégico Institucional, el Plan Operativo de nuestra Facultad y las actividades contenidas en el Programa de Gobierno ofrecido y enriquecido con los aportes de los docentes, estudiantes y personal administrativo, que conforma la comunidad universitaria, con el propósito de generar los cambios y los procesos de desarrollo que consoliden la importancia de la calidad y la pertinencia de la Educación Superior en prevención y solución de los grandes problemas nacionales.

\section{Considerando}

\section{I}

Que las recientes elecciones de autoridades de los Consejos de Facultad en la UNANManagua revelan la fortaleza y madurez institucional de nuestra universidad en el marco de su autonomía plasmada en la Ley 89 .

\section{II}

Que es necesario seguir promoviendo el trabajo colectivo, la gestión, ejecución y evaluación de este máximo órgano de gobierno de la Facultad de forma dinámica y con calidad.

\section{III}

Que dicho fortalecimiento se enmarca en el contexto de desarrollo de nuestros planes estratégicos guiados por el compromiso con nuestro pueblo. 


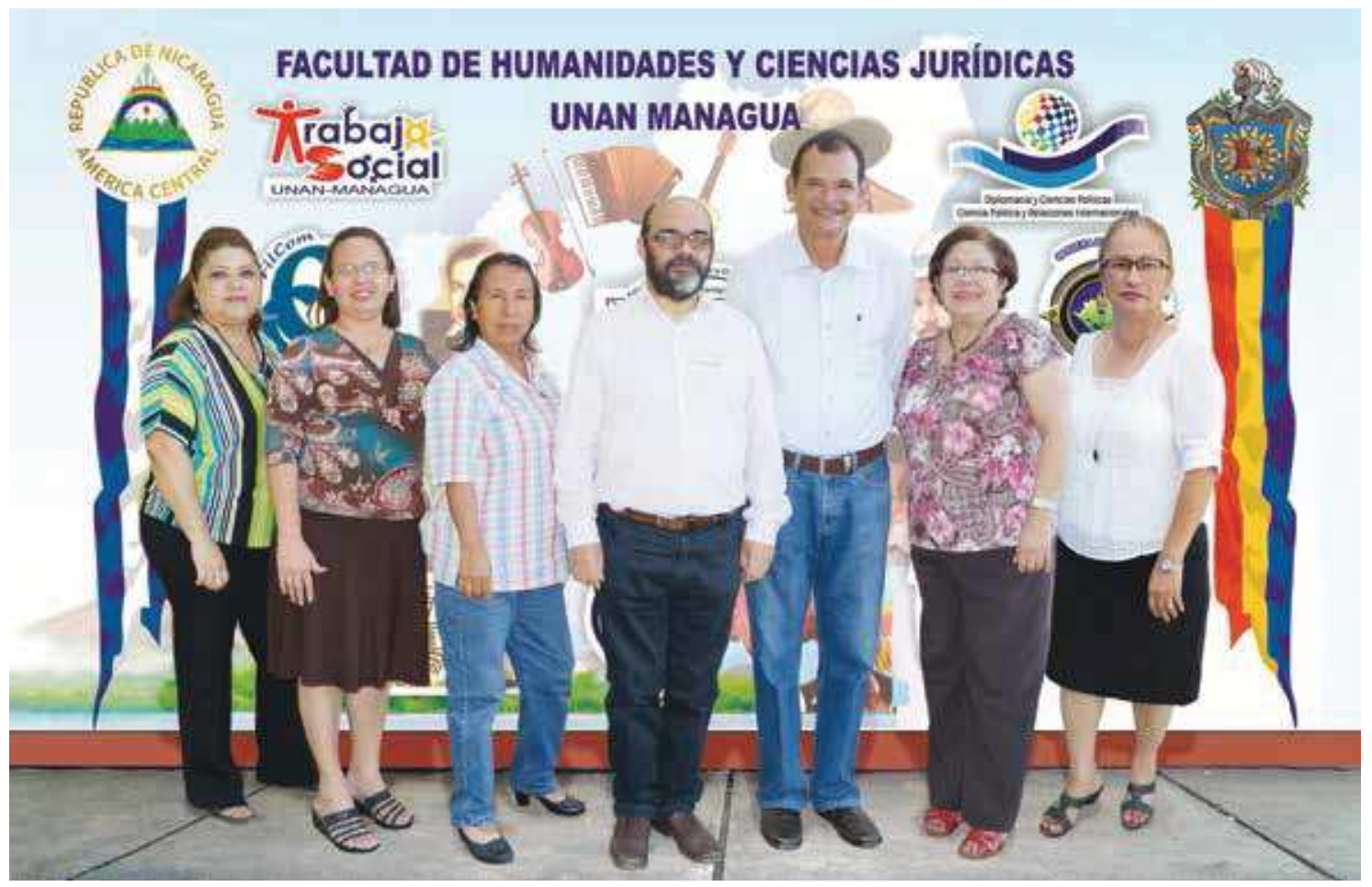

\section{Declaramos}

1. Dar inicio de manera solemne al período de sesiones del Consejo de Facultad de Humanidades y Ciencias Jurídicas para el período 2014-2018.

2. Nuestro compromiso de seguir desarrollando, con más ahínco y compromiso el trabajo institucional en los distintos aspectos centrales de nuestra actividad cotidiana, particularmente en lo concerniente al proceso de enseñanza aprendizaje, investigación, extensión y proyección social, como fundamento de la relación de la universidad con la sociedad.

3. Nuestro decidido interés de promover con calidad la participación de todos los estamentos universitarios de facilitar el desarrollo integral de nuestra Alma Mater.
4. En este sentido, resulta clave como factor fundamental el dinamismo y espíritudecompromiso del movimiento estudiantil como protagonista de los cambios presentes y futuros.

5. Seguir contribuyendo de forma decidida al fortalecimiento integral de toda la universidad aportando todo nuestro esfuerzo para hacer cada día una mejor institución al servicio de los ciudadanos y ciudadanas.

6. Cumplir hacer cumplir nuestras leyes y reglamentos, velando por los intereses de los más humildes.

7. Hacer un llamado a todos los sectores y actores de la Facultad a contribuir cada día más con nuestro compromiso enmarcado en la misión, visión y valores universitarios y el apego a los intereses populares. 
8. Tener siempre presente en nuestro trabajo diario el ejemplo de universitarios y universitarias que aportaron incluso su vida para el pleno desarrollo de los y las nicaragüenses.

Managua, Recinto Universitario “Rubén

Darío", 24 de junio de 2014.

¡A la libertad por la Universidad! 